Editorial

\title{
New technologies and the future of cardiology: journal of cardiology \& current research
}

\section{Editorial}

I am honored to be in Editorial Board of this brand new journal hoping that The Journal of Cardiology \& Current Research has a bright future. It is important for JCCR to be open for all practicing cardiologist and researchers from all countries around the world regardless of whether they are developed or undeveloped. The main goal is to give a chance for a "Step into the World of Research to all.

If we talk about future of cardiology, it is clear that modern technologies will be of the greatest importance. The future is in interventional cardiology, cardiac implants and devices, use of stem cells in various cardiac diseases, and probably the most important: implementation of a various digital technologies. It is clear that, we shall see a huge development of e-Health, m-Health, and mobile phone apps for prevention and follow up of the most important cardiac diseases as well as in a field of robotics, artificial intelligence, telemedicine and various imaging technologies.

As pediatric cardiologist, I have a personal opinion that is also important to save skills of bedside medicine to avoid noncritical use of modern technologies and to keep a human approach to cardiac patients. There is still a place for classical cardiac auscultation - using acoustic stethoscopes and a modern auscultation - using electronic stethoscopes with various possibilities of sound processing of heart sounds and murmurs. I like modern technologies but still like and my stethoscope although many doctors, especially from developed

\author{
Volume I Issue 3 - 2014
}

Zeljko Roncevic

Department of Pediatric Cardiology, Mostar University Medical

School, Bosnia and Herzegovina

Correspondence: Zeljko Roncevic, Department of Pediatric Cardiology, Mostar University Medical School, Bosnia and Herzegovina, Tel 38-76-33I-8228,

Email zroncevicl 12@gmail.com

Received: June 20, 20I4 | Published: July 0I, 2014

countries, are talking about the death of this iconic 200 years old instrument. The echo is powerful in experienced hands but I'm still surprised (from time to time) how interesting sounds human heart can produce. In the end, I invite all who can contribute to this open access journal to do it, all are welcome in a praise worthy way of increasing human knowledge.

\section{Acknowledgments}

None.

\section{Conflicts of interest}

Authors declare that there are no conflicts of interest. 